\title{
GOVERNANÇA EM REDE: sentidos que se deslocam no movimento da formação continuada de professores alfabetizadores
}

\author{
Ana Paula Pereira Marques de Carvalho \\ Universidade do Estado do Rio de Janeiro - UERJ, Brasil \\ Nataly da Costa Afonso \\ Universidade do Estado do Rio de Janeiro - UERJ, Brasil
}

Resumo

\begin{abstract}
A crescente parceria entre o setor público e privado mobilizam novas formas de governança em rede no âmbito das políticas curriculares. Neste contexto, chama-nos atenção as ações de um Instituto brasileiro - o Instituto Natura -, vinculado à empresa brasileira Natura Cosméticos S. A., no cenário político-educacional brasileiro. Considerando a relação entre novos sujeitos políticos que compõem o terceiro setor em prol da educação, tomamos um dos projetos do Instituto - o Projeto Trilhas como exemplo para problematizar as tentativas de regulação e fixação de sentidos para a prática docente no movimento de formação continuada dos professores alfabetizadores. Subsidiadas em Homi Bhabha, percebemos o deslocamento de uma autoridade que estimula a produção de uma vitrine de "boas práticas", mobilizada através do Trilhas, movimentando uma noção de experiência como algo que inspira e, por isso, merece ser compartilhado e reproduzido. A noção de experiência docente que defendemos, em diálogo com as discussões derridianas, relaciona-se à ideia de acontecimento que nos coloca no lugar da imprevisibilidade, da experiência como algo único, subjetivo e singular, que se afasta da ordem do cálculo, visando a uma outra dimensão para o protagonismo docente: aquele que também tem o direito de significar o que entende por prática docente.
\end{abstract}

Palavras-chave: Políticas curriculares; Projeto Trilhas; Formação de professores alfabetizadores; Redes Transnacionais de Influência.

\begin{abstract}
The growing partnership between the public and private sector mobilizes new forms of networked governance within the scope of curriculum policies. In this context, the actions of a Brazilian Institute - the Natura Institute -, linked to the Brazilian company Natura Cosméticos S. A., call our attention in the brazilian political-educational scenario. Considering the relationship between new political subjects that is part of the third sector in favor of education, we take one of the Institute's projects - the Trilhas Project - as an example to throw into question the attempts to regulate and fix meanings for teaching practice in the continuing education movement of literacy teachers. Subsidized in Homi Bhabha, we perceive the displacement of an authority that stimulates the production of a showcase of "good practices", mobilized through Trilhas, moving a notion of experience as something that inspires and, therefore, deserves to be shared and reproduced. The notion of teaching experience that we defend, in dialogue with Derridian discussions, is related to the idea of event that puts us in the place of unpredictability, of experience as something unique, subjective and singular, which moves away from the order of calculation, aiming at another dimension for the teaching protagonism: the one who has the right to mean what he understands by teaching practice.
\end{abstract}

Keywords: Curriculum policies; Trials Project; Literacy teachers education; Transnational Influence Network. 


\section{Introdução}

As questões que hoje movimentam as políticas curriculares tocam nas fronteiras tênues entre o público e privado, em que o privado está sendo construído - e festejado - por dentro do público. Ao longo dos anos, muitas pesquisas na área de política educacional têm se debruçado sobre os diversos movimentos das parcerias público-privadas e as forças genéricas em prol das forças do mercado. Peroni, Oliveira e Fernandes (2009) ao analisarem as conexões entre o público-privado, destacam estratégias neoliberais que endossam uma crise do Estado. Porém, as autoras ressaltam que dentro do movimento neoliberal, há tendências diferenciadas sobre as novas configurações no que tange à responsabilidade pelas políticas sociais: a teoria neoliberal propõe o repasse da responsabilidade social para o mercado, inclusive subsumindo a interferência do Estado.

Já a chamada terceira via propõe o repasse da responsabilidade das políticas sociais para a sociedade civil, representada pelo público não-estatal, articulando-se ao Estado, sob a justificativa de que o mundo não pode ser compreendido como um grande mercado. $\mathrm{O}$ "controle social" deve, então, ser assumido pelo terceiro setor: organizações nãogovernamentais, instituições filantrópicas e comunitárias e outras associações similares que, de acordo com as autoras, têm preconizado questões mais democráticas. E o objetivo desses organismos é "prover serviços sociais na área de saúde, educação, proteção contra o crime, alívio à pobreza e têm em comum o fato de serem não-lucrativos e fazerem parte da sociedade civil" (Peroni; Oliveira; Fernandes, 2009, p. 768).

Assim, sob esse e aquele viés de ingerência neoliberal, vivenciamos novas formas de governança que se demarcam por um mercado de autoridades com a participação de novos sujeitos políticos. O setor público está mais congestionado e formas de relacionamento estão sendo estabelecidas dentro da política, numa arquitetura global com novos agenciamentos que tentam capturar e modelar os conhecimentos de política, inclusive, alterando objetivos estatais, bem como a capacidade do Estado de projetar o seu poder na sociedade mais abrangente (Ball, 2014). Nesse processo, o que se percebe é uma mudança na forma de governo em que, de acordo com as pesquisas de Ball (2014), redes passam a compor as relações políticas e o Estado muda de prestador para contratante do "desenvolvimento" e de políticas de ajuda.

Nesse movimento das novas governanças, Ball (2014) destaca as Redes Transnacionais de Influência (TANs) que diferem de outros tipos de redes, uma vez que estão voltadas para princípios, ideias e valores, intercambiando discursos para mudar a percepção do público sobre problemas sociais. O movimento das novas governanças é uma questão importante a ser problematizada nas análises da intrincada relação entre esses novos sujeitos políticos, que estão contribuindo para um processo de espetacularização de uma crise educacional no Brasil. Macedo (2013) considera que o discurso de crise na educação é constantemente mobilizado como estratégia para fixação de um novo sentido, que se pretende homogêneo. A falta de qualidade na educação aparece como justificativa na formulação das políticas curriculares, que utilizam dados quantitativos de avaliações externas como comprovação daquilo que falta. Tal discurso age como uma "mola propulsora de mudança" (Macedo, 2013) 
e diferentes discursos particulares buscam se hegemonizar como a solução ideal, "vendendo" soluções para a superação da crise e mobilizando novas formas de governança, com forte influência do terceiro setor na educação pública do país.

Ball (2014), em suas pesquisas, tem mapeados as redes, das quais fazem parte o terceiro setor, a partir do método de etnografia de redes, destacando afiliações e co-afiliações entre pessoas e instituições e entre instituições e instituições, atentando para as mudanças do Estado de governo para governança - em ação (Ball, 2014). Para Ball (Avelar; Ball, 2017), isto significa uma análise para além de relações burocráticas hierarquizadas, ou seja, trata-se da necessidade de um mapeamento sobre as heterarquias entre Estado, mercado e novas filantropias cujas relações estão cada vez mais turvas, diversas e flexíveis. Inspiradas no método de etnografia de redes (Ball, 2014), temos pesquisado o fluxo do terceiro setor e de propostas político-curriculares nas páginas na internet, vídeos, páginas do Facebook, blogs, tweets, dinamizadas nos ambientes virtuais, principalmente, no alinhamento à Base Nacional Comum Curricular (BNCC).

São propostas que estão sendo apresentadas como garantidoras dos mesmos direitos para todos, através da oferta do mesmo conhecimento e das mesmas possibilidades de desenvolvimento de habilidades e competências em todos os alunos, fortalecendo supradiscursos que operam com uma lógica do capital humano na busca pela competitividade, espírito de equipe e necessário engajamento em programas sociais e de instrumentalização, transferindo a responsabilidade pelo sucesso para os indivíduos, via autossujeição e autocontrole. Essa é uma linguagem política em torno do eficientismo que enfatiza as responsabilidades individuais e contribui para novas paisagens políticas neoliberais, deslocando o sentido de público com novas configurações entre "público, privado, filantrópico, não-governamental" (Macedo; Ranniery, 2018, p. 740).

Importante ressaltar que esse olhar para os ambientes virtuais implica em outras possibilidades de significação política, enfatizando que as questões político-curriculares também vêm sendo propagadas através das aceleradas formas de comunicação. Entendemos que o virtual não é o único "contexto" possível para as disputas pelos sentidos políticocurriculares, mesmo porque argumentamos que a política não se circunscreve a esse ou aquele local (Lopes; Cunha; Costa, 2013). Mas, corroboramos com a ressalva de Derrida (Derrida; Stiegler, 2002) sobre a força do virtual que deixa sua marca no evento produzido, no tempo, no espaço da imagem, no discurso e na informação. Ao mesmo tempo, o virtual também nos expõe a eventos que não podem ser previstos, reduzidos ao fato de que algo vai acontecer. Derrida (Derrida; Stiegler, 2002) exemplifica que se soubermos que vai chover, isso não pode ser considerado um evento. Por isso, quando o filósofo menciona o virtual, propõe um futuro aberto como axioma da desconstrução e associa esse futuro imprevisível ao duplo como o resto ou rastro que incentiva uma tendência para a confusão.

Portanto, sob a perspectiva desconstrucionista derridiana, entendemos o virtual como "[...] um tecido, uma composição heterogênea feita de muitos fios, os quais uma vez entrelaçados implicam múltiplas camadas de leitura" (Nascimento, 2004, p. 15 apud Lopes; Cunha; Costa, 2013, p. 398), mas de intensa potência discursiva, que temos buscado 
problematizar no jogo político que envolve propostas para formação continuada de professores, sendo dinamizadas nessas Redes Transnacionais de Influência.

Um dos Institutos brasileiros que nos chama atenção é o Instituto Natura que, através de vários projetos educacionais e de parcerias com outros Institutos e Fundações, vem propagando questões sobre responsabilidade, atuação conjunta, rede de parceiros, como solução para os problemas educacionais: "somos todos responsáveis por uma educação de qualidade", "a paixão pela educação é o que nos move”, "atuar conjuntamente para melhorar a educação", "ao lado de uma rede de parceiros, executamos e apoiamos projetos voltados à melhoria da educação brasileira, no Brasil e na América Latina, acreditando na transformação social por meio da educação equânime e de qualidade" (Instituto Natura, 2016).

O Instituto Natura é "uma associação sem fins lucrativos ou econômicos, com prazo de duração indeterminado" (Instituto Natura, 2018a), vinculada diretamente à empresa Natura Cosméticos S.A, uma empresa brasileira que comercializa produtos de tratamento para o rosto, corpo, sabonetes, barba, desodorantes, óleos corporais, maquiagem, perfumaria, cabelos, proteção solar e materiais de papelaria. Juntamente com a Fundação Lemann e com a Associação Bem Comum, o Instituto Natura faz parte da chamada "Parceria pela Alfabetização em Regime de Colaboração" (PARC), que assume como objetivo oferecer suporte técnico e apoio às Secretarias Estaduais de Educação para que os alunos sejam alfabetizados na "idade certa". Tal parceria tem como foco o ensino da Língua Portuguesa, a produção de material didático, formação de professores e a avaliação de fluência dos estudantes, além das chamadas políticas de incentivo dos estudantes (Todos pela Educação, 2019).

Neste artigo, tomaremos como foco um dos projetos de formação continuada dos professores alfabetizadores que faz parte do PARC e vem sendo dinamizado pelo Instituto Natura: o Projeto Trilhas, criado 2009, através da parceria entre o Instituto Natura e a Fundação Telefônica Vivo. Nosso intuito, ao suscitar questões sobre o Projeto Trilhas, é problematizar as tentativas de regulação da prática do professor alfabetizador que vem sendo propagada através do estímulo para que os professores cursistas - ou trilheiros, como são chamados - publiquem vídeos no YouTube - inclusive como condição para obtenção do certificado - utilizando os materiais do Projeto em suas salas de aula, de acordo com as rotinas e uso dos materiais apresentados no Curso, seguindo o roteiro proposto pelo Projeto.

Assim, em diálogo com a perspectiva de governança de Bhabha (2013), consideramos importante discutir as tentativas de regulação que têm sido propagadas na intrincada relação entre novos sujeitos políticos. Sob esse enfoque, pretendemos interpelar a autoridade que envolve o Projeto Trilhas, em meio a imagens, também produzidas virtualmente, que tentam fixar sentidos para a prática docente e, ao mesmo tempo, o sentido da própria rede, reunindo signos de aprovação e aceitação, em nome de um consenso sobre a prática de leitura, escrita e formação de professores alfabetizadores que nos apresenta a temporalidade como uma historicidade linear e homogênea, como se fosse possível projetar um futuro para o trabalho docente, um horizonte a ser alcançado em sala de aula, para o alcance de um país alfabetizado. 


\section{Que Trilhas estamos pactuando?}

O Projeto Trilhas foi aprovado no Guia de Tecnologias do Ministério da Educação, sendo reconhecido como uma tecnologia eficaz e importante junto às metodologias e projetos de alfabetização, já desenvolvidos em escolas públicas do país (Instituto Natura, 2015a), com vistas ao enfrentamento da crise educacional e, mais especificamente, ao aumento dos índices de alfabetização, articulando-se a outras políticas públicas curriculares voltadas para a formação continuada de professores alfabetizadores, como o Pacto Nacional Pela Alfabetização na Idade Certa (PNAIC), criado em 2012.

As ações do PNAIC foram apresentadas como estratégicas no âmbito das políticas públicas, voltadas, prioritariamente, para a formação continuada de professores, através do compromisso entre os governos federal, Distrito Federal, Estados e Municípios de "assegurar que todas as crianças estejam alfabetizadas até os oito anos de idade, ao final do $3^{\circ}$ ano do Ensino Fundamental" (Laboratório de Educação, 2014; Ministério da Educação, 2012). Percebemos um movimento sobre sentidos de pactuação pela alfabetização em torno de quatro eixos: ações articuladas entre diferentes instâncias federativas, formação, avaliação, e elaboração de materiais pedagógicos. Esse Programa teve uma considerável abrangência no território brasileiro, com uma expressiva adesão, conforme os dados fornecidos pela Secretaria de Educação Básica (SEB) do Ministério da Educação, em 2014 (Frangella, 2016).

O PNAIC é considerado por Martins, Axer e Lucena (2021) como uma estratégia política que contribui para a formação de uma "produção curricular comum e nacional" (p. 61), pautado no discurso em prol de uma educação plena. Destaca-se, nesse sentido, suas ações voltadas para a formação de professores como um dos eixos em que se articulam diferentes atores sociais e ações em torno do objetivo anunciado de garantir a alfabetização plena e "no tempo certo". Corroboramos com as autoras ao compreenderem o PNAIC como um movimento político de produção curricular, uma vez que suas ações mobilizam sentidos para pensar e produzir currículos no cotidiano escolar.

Apesar de ter ampla mobilização, o PNAIC não foi o único programa de formação de professores alfabetizadores que se respaldou na ideia de um pacto pela alfabetização. No Ceará, o Programa Alfabetização na Idade Certa (Paic), de 2007, visava a uma política cooperativa entre o Estado e os Municípios para apoiar a formulação e implementação de políticas voltadas para o direito à educação, com foco específico na alfabetização das crianças das redes públicas do Ceará até os sete anos de idade. Esperava-se contribuir para o alcance deste objetivo, atuando na formação continuada de professores e apoio à gestão escolar, dentre outras ações. O programa sofreu modificações ao longo dos anos, expandindo suas ações até o $5^{\circ}$ ano $($ Paic +5$)$ e, posteriormente, até o $9^{\circ}$ ano do Ensino Fundamental (MAIS PAIC) (Instituto Natura, 2018b).

Outro pacto também firmado pelo Governo do Estado do Espírito Santo e as redes municipais de ensino da região foi o Pacto pela Aprendizagem no Espírito Santo (PAES) que abrangia desde a Educação Infantil até as séries finais do Ensino Fundamental, sendo estruturado em três eixos de trabalho: apoio à gestão, fortalecimento da aprendizagem, planejamento e suporte. A premissa do PAES é que "exista apenas o aluno da rede capixaba, 
e não mais da rede estadual ou municipal de ensino"2, com o objetivo de se alcanças melhores indicadores educacionais, através de ações conjuntas. A parceria entre a Secretaria do Estado do Espírito Santo e o Instituto Natura, através de seus referidos projetos, é propagandeada no site do Portal Trilhas como uma das grandes ações do PAES, ao enaltecer as possibilidades de formação dos professores capixabas. A formação, intitulada "Nas Trilhas com Paes", é um dos pilares dessa parceria com distribuição de kits dos materiais produzidos pelo Trilhas nos cursos de formação dos mediadores (Instituto Natura, 2018b).

Assim, percebemos que a preocupação com a formação de professores alfabetizadores e com a alfabetização, como um todo, tem mobilizado diferentes políticas, pactos e bases que enfatizam suas ações para os docentes dos anos iniciais do Ensino Fundamental. Nesse movimento político, os objetivos do Projeto Trilhas se entrecruzam com a proposta do PNAIC, uma vez que o Trilhas compartilha as mesmas metas e maneiras de atuação:

- Eixo de trabalho voltado para a formação continuada, presencial e a distância, com foco na alfabetização.

- Distribuição de materiais de apoio articulados ao Programa Nacional Biblioteca da Escola (PNBE) e complementação de jogos pedagógicos.

- Atuação em regime de colaboração com governos federal, estadual e municipal.

- Uso de portais virtuais como apoio para o desenvolvimento das ações (Instituto Natura, 2015b).

Mais ainda, o Trilhas visa ao aprimoramento das competências dos professores alfabetizadores e de estudantes de Pedagogia no trabalho de leitura e escrita em sala de aula, sendo desenvolvido sob três eixos: a) Kit Trilhas: material didático (impresso e on-line), b) Portal Trilhas e c) Curso a distância (EAD), veiculado no Portal Trilhas. Cada um desses itens vem sofrendo alterações ao longo dos anos e parece variar nas suas posições de destaque no movimento do Projeto.

Atualmente, destacamos a articulação do Trilhas com a Base Nacional Comum Curricular (BNCC), como aponta o relatório do Instituto do ano de 2019:

A incorporação de uma Base Nacional Comum Curricular (BNCC) para a Educação Infantil e o Ensino Fundamental foi um grande avanço para a educação pública, sendo um importante referencial sobre as habilidades necessárias a todos os docentes. Assumimos o compromisso de levá-la para a sala de aula, de forma contextualizada, ajudando o professor com o uso de recursos didáticos de qualidade (Instituto Natura, 2019).

Com a aproximação do Projeto à BNCC, o Curso EAD ganhou destaque, com novo título "Leitura em Voz Alta pelo Professor", passando a articular seus objetivos à Base, através da promessa de que auxiliará o professor "a integrar, em seu planejamento de aula, as habilidades previstas na BNCC” (Instituto Natura, 2019):

Para formar leitores 
Livros são a porta de entrada para o mundo das letras! E ajudar os educadores a explorar de forma adequada a linguagem oral com seus alunos e transformar o processo de alfabetização em uma jornada cheia de possibilidades é o foco do curso de educação a distância lançado em 2018: Leitura em Voz Alta pelo Professor. Com vídeos, textos, imagens e apoiado na experiência prática do educador em sala de aula, a formação tem carga horária de $45 \mathrm{~h}$ e está alinhada aos parâmetros da Base Nacional Comum Curricular (BNCC). Em 2018, foram mais de 8,8 mil concluintes do curso, que receberam certificado emitido por instituição reconhecida pelo Ministério da Educação (Instituto Natura, 2019).

Nesse sentido, o Projeto faz parte de um movimento discursivo que enaltece uma base comum curricular como necessária para organizar a educação brasileira - e para aplacar a crise -, tomando a sala de aula como o fim precípuo para que essas orientações possam - em nossa opinião, ilusoriamente - tornar-se realidade. O que se percebe é o deslocamento de um movimento discursivo que destaca a "Educação como um direito de todos", a ser pretensamente garantido através de movimentos pela educação, "num exercício de colaboração mútua" (Ramos, 2017). Nesse jogo de significação sobre a necessidade de regimes de colaboração para que os planos de educação logrem sucesso, a Base Nacional Comum Curricular (BNCC) contribui para o afloramento do desejo de controle e centralização curricular, sob o argumento de que enfrentamos baixos níveis de educação e da necessidade de incremento à formação dos professores, conforme Macedo e Frangella (2016, p.1) observam:

A discussão atual de uma base comum em nível nacional para o currículo mobiliza toda essa história, deslocando-a no tempo e no espaço - ou hibridizando esses e outros discursos, o que dá no mesmo - para produzir argumentos em defesa ou contra a centralização curricular. Por outro lado, no mundo conectado em que vivemos, também marcado por estratégias globais de (impossível) controle das formas de representação, as experiências internacionais marcam inexoravelmente o nosso debate. Não é apenas no Brasil que o desejo de controle nacional dos currículos vem se manifestando. Desde os anos de 1990, com o que criticávamos à época como políticas neoliberais, os governos aprimoraram tanto mecanismos de avaliação centralizada quanto o controle mais direto dos currículos, justificando-o por supostos baixo nível da educação e formação deficiente de professores. Ainda, por exemplo, que no Brasil se tenham produzido, nos últimos anos, inúmeras intervenções na interiorização das universidades e na melhoria da qualificação de professores, o discurso da falta de qualidade segue justificando as políticas.

A aproximação do Trilhas à Base Nacional Comum Curricular (BNCC), apontada, atualmente, como o eixo mobilizador do Projeto, suscita a problematização encaminhada por Frangella e Dias (2018) no que diz respeito ao caráter normativo e regulatório da Base, figurando como uma estratégia para responder às desigualdades do campo educacional. Assim, sob a ideia de justiça, democracia e igualdade, tenta-se estabelecer normas para as 
práticas dos docentes, apresentadas como resposta/solução política para o possível fracasso escolar. O Trilhas vem fortalecendo sentidos sobre questões normativas e regulatórias, e é esse movimento da autoridade que destacamos, vinculado a uma produção discursiva sobre a importância de estar em rede e participar das ações inspiradoras no campo da alfabetização. Um dos vieses para o estímulo à propagação de ações inspiradoras é o incentivo para que os professores publiquem vídeos no YouTube, utilizando o material do Trilhas, de acordo com o roteiro proposto no Curso EAD.

Assim, sob a promessa de que seguindo esse roteiro, o Trilhas contribui para o aperfeiçoamento das competências dos professores no trabalho com leitura e escrita em sala de aula e, mais recentemente, sendo apontado como um articulador entre as práticas em sala de aula e as habilidades propostas pela BNCC, as redes transnacionais das quais o Projeto faz parte, transitando nos espaços virtuais, vão tentando construir efeitos de realidade como formas de regulação, produzidos sob a ideia de uma transparência discursiva. Segundo Bhabha (2013, p.181-182),

A transparência é a ação da distribuição e organização de espaços, posições e saberes diferenciais em relação uns aos outros, relativos a um sentido discriminatório, não inerente, de ordem. Isto efetua uma regulação de espaços e lugares que é designada de forma autorizada; ela coloca o destinatário no enquadramento para alguma ação ou resultado [...]. A transparência realiza um efeito de autoridade no presente (e uma presença autorizada) através de um processo ao que Michel Foucault descreve como "efeito de finalização, relativo a um objetivo", sem sua necessária atribuição a um sujeito que elabora a lei proibitória: farás ou não farás".

Nesse sentido, argumentamos que o Projeto Trilhas, no jogo político em que se movimentam outros projetos político-curriculares, tem contribuído para a mobilização de uma autoridade que tenta espraiar modos de governança sobre a prática de professores alfabetizadores, como parte de uma estratégia que produz regras de reconhecimento sobre a importância do Trilhas no cenário educacional brasileiro, envolvendo também o jogo entre o psíquico e o afetivo, inerentes aos movimentos políticos. Bhabha (2013) questiona o projeto colonial que se espraia na Índia, através da introdução e disseminação da Bíblia, pois carrega uma ambição intervencionista na intenção de fazer eclodir uma Índia inglesa de língua e cultura homogêneas. Essa ambição desenhou o plano educacional à época para que todos se afeiçoassem à Missão da Cruz, derrubando, assim, a própria religião daqueles considerados pagãos.

Entendemos que o Trilhas faz parte de um amplo "estatuto de verdade" que vem tentando hierarquizar, normalizar sentidos, organizar saberes no processo político, numa suposta plenitude temporal, visando, inclusive, à preservação da autoridade num modelo de governança, através da proposição de soluções para os problemas educacionais, colocandose como um importante parceiro para a transformação social. Contudo, julgamos importante que a batalha pelo estatuto da verdade, em que o Projeto Trilhas está inserido, seja examinada de modo que a transparência não seja tratada ingenuamente, pois a autoridade segue 
circulando, disputando o direito de controlar conhecimento e formação docente e, por isso, o direito de inspecionar - em prol da garantia, por exemplo, do direito à alfabetização.

Em diálogo com Bhabha (2013), é possível pensar que a autoridade nunca está do lado de fora ou em oposição implacável às nossas relações. Ela é uma pressão e uma presença que age constantemente, embora de forma desigual, ao longo de toda a fronteira da autorização, entre a noção de disposal, como consentimento de uma moldura referencial, e disposition, "no sentido de inclinação mental, estado de espírito" (Bhabha, 2013, p. 182). Ou seja, na superfície entre o que Bhabha (2013) denomina disposição-como-outorga e disposiçãocomo-inclinação, o Trilhas transita através de imagens de pacto e coesão, na formação de comunidades - imaginadas - e propagandeia a atualidade como a superfície de um grande vitral cuja adoção de um roteiro é apresentada como possibilidade de sucesso e aprimoramento das práticas pedagógicas dos alfabetizadores. Porém, ao mesmo tempo, o Trilhas é produzido sob o signo da diferença que envolve processos de repetição que nunca produzirão o mesmo resultado, a mesma imagem, a mesma ação. Essa impossibilidade de um mesmo resultado desloca resistências, que não significam uma simples oposição, tampouco a negação das propostas que envolvem o projeto Trilhas.

Desse modo, analisar o processo político-curricular como um processo meramente contraditório seria simplificar as relações de poder e manter a polarização entre dominantes e dominado. No nosso entendimento, os processos se deslocam sob os efeitos da ambivalência (Bhabha, 2013) que demarcam as possibilidades outras que são sempre produzidas no interior das regras da autoridade, no caso, em torno do Projeto Trilhas. As possibilidades outras dizem respeito aos signos duplicados que mobilizam sentidos num processo em que a autoridade constitui-se como algo fronteiriço, intersticial, deslocada entre a moldura de referência e o estado de espírito que se movimenta em função do rompimento contínuo dos significados sobre o processo de leitura e escrita, bem como sobre o papel do professor, especificamente do professor alfabetizador, enunciando outros sentidos para o Projeto Trilhas. As tentativas de fixação de sentidos sobre o trabalho do professor alfabetizador abrem fendas na sua prática em sala de aula, em decorrência da impossibilidade da reprodução, de forma idêntica, das ideias que aquela autoridade tenta estabelecer. Por conseguinte, defendemos a docência como experiência experimentada que continuamente rompe as formas prontas das propostas para o trabalho em sala de aula.

\section{A docência como experiência: imprevisibilidades e produção curricular}

Consideramos que ao ter como eixo principal a formação de professores alfabetizadores, o Projeto Trilhas vem trazendo significações para o ser docente. Afinal, o que deve saber o professor alfabetizador? Quais são as práticas e experiências válidas e que precisam ser compartilhadas? O que é a experiência docente destacada em muitos documentos de orientação do Projeto Trilhas? Nesse sentido, propomos reflexões sobre a docência enquanto experiência e, ainda, os sentidos de experiência imbricados neste percurso. 
A experiência docente é acionada no Trilhas no estímulo à troca de experiência entre os docentes, sendo este ponto abordado em diferentes espaços do Projeto, como, por exemplo, no módulo do curso "Leitura em Voz Alta pelo Professor", em que há uma aba para "Experiências Inspiradoras" do portal, dentre outros momentos.

[...] um programa de formação pensado especialmente para você, que faz parte do universo da alfabetização! Os ciclos de formação contam com ações presenciais e a distância, que serão desenvolvidos ao longo de todo ano e oferece certificado emitido pela SEDU. Gestores, pedagogos e professores unidos, trocando experiências pela transformação da alfabetização e multiplicação de novas práticas de ensino. Conheça o curso de Leitura em Voz Alta pelo professor e prepare-se para os encontros presenciais dessa jornada de conhecimento (Instituto Natura, 2019, grifos nossos).

A ideia de experiência, no entanto, é apresentada como uma bagagem acumulada e, portanto, cabível de ser compartilhada como indicador de uma competência que lhe confere certa autoridade no assunto. A troca de experiências previamente selecionadas, oferece-nos uma vitrine de "boas práticas" que devem servir de inspiração aos alfabetizadores em formação, mobilizando sentidos do que é ser um bom professor e quais práticas são consideradas válidas nesse processo e adjetivadas como inspiradoras. Como estímulo ao que chamam de "boas práticas", o Instituto Natura desenvolveu os projetos "Rede que Ensina" e "Município Leitor", como ações de reconhecimento do Projeto Trilhas, para premiar os professores e gestores no desenvolvimento de "boas práticas na educação".

Ambos os projetos tinham como objetivo dar visibilidade às práticas de formação de leitura nas escolas de diferentes Municípios. Os gestores deveriam listar as ações, promovidas em suas escolas, que mobilizassem o maior contato com os livros e o hábito da leitura em suas comunidades escolares. Os Municípios premiados receberam um acervo de livros. Além disso, o projeto "Rede que ensina" também estimula a publicação de vídeos pelos professores de todos os Estados e Municípios.

Área de compartilhamento de experiências com o TRILHAS. Participe assistindo aos vídeos de professores de todo o Brasil: você pode "curtir" os que considerar mais significativos e colocar seus comentários. E você, professor que trabalha com o projeto, selecione uma prática, grave um vídeo em que ela esteja evidente e registre na área. Vamos trocar experiências e formar uma Rede que Ensina! (Instituto Natura, 2019).

Ao destacarmos a docência enquanto experiência, propomos um olhar diferente para este termo, em diálogo com os estudos de Camões (2019) que nos ajuda a pensar a experiência como um acontecimento.

[...] a experiência se alinha a uma forma singular, finita, contingente e o saber da experiência acontece na relação entre o conhecimento e a vida, tem a ver com a 
elaboração de sentido, e, desse modo, está ligada a existência do sujeito ou de um grupo em particular, de modo que a significação da experiência, ainda que parta de um mesmo acontecimento, acontece de maneira singular para cada sujeito (Camões, 2019, p. 88).

Perceber a experiência como um acontecimento subjetivo e singular nos afasta da ideia de experiência como algo a ser reproduzido, com base em supostas "boas práticas" que precisam ser disseminadas. O acontecimento, para Derrida (apud Filho, 2012), está ligado ao inesperado. Trata-se da imprevisibilidade e indecidibilidade que produzem a experiência, que não pode ser antecipada ou, sequer, posteriormente reproduzida. Partilhar experiências é compreendido como uma prática discursiva tradutória, pensando a tradução enquanto partilha e negociação de sentidos ambivalentes. Um acontecimento, explica Derrida, não chega nunca "na horizontal" e não se perfila no horizonte de onde se poderia prevê-lo. Um acontecimento se irrompe como surpresa absoluta (apud Filho, 2012).

Siscar (2012) argumenta que a tradução é vista - tradicionalmente - como a transferência de significados, ou seja, a simples transferência de sentidos de uma língua para outra ou de um sistema de signos para outro, por exemplo. Entretanto, nesse movimento, aquilo que poderia ser compreendido como o acontecimento original se perde. Cabe destacar que a tradução não é a transferência entre idiomas ou transferência dentro de uma mesma língua. "A tradução constitui, por assim dizer, uma passagem ao discurso - que é o elemento no qual nos encontramos" (Siscar, 2012, p. 153).

A teoria da tradução defende, portanto, que o texto ou sentido original não existem sem uma leitura anterior. Logo, é o próprio ato de tradução que cria o original, que produz sentidos:

Não haveria texto ou sentido original antes de uma leitura. Aquilo que chamamos de original se estabelece e se modula segundo as diversas interpretações de um texto, que dessa maneira perde qualquer essência ou significado intrínsecos. O sentido original é o sentido que lhe atribui um leitor ou uma determinada situação interpretativa, um determinado contexto de leitura. O argumento pode ser resumido da seguinte maneira: não existe original antes de sua tradução, é a tradução que, de alguma maneira, cria seu original (Siscar, 2012, p. 168-169, grifos do autor).

Ao tentar reproduzir, há algo que sempre escapa e é produzido de maneira diferente (Bhabha, 2013). Sendo assim, a tentativa de tradução marca a impossibilidade de tradução total, pois o discurso cria a realidade a qual busca traduzir. Portanto, entendemos que na tentativa de partilhar experiências, não há possibilidade de uma transparência e de uma verdade, mas apenas diferentes experiências que são reiteradamente traduzidas e criadas. A experiência docente como acontecimento nos coloca no lugar do indecidível, daquilo que não pode ser recriado ou reproduzido, no lugar do que Derrida chama de incalculável. A condição de possibilidade, de antecipação, para o autor, impossibilita o acontecimento e, portanto, a experiência. 
A ideia de boas práticas e o estímulo à reprodução de vídeos, a partir dos marcos estabelecidos, funcionam como tentativas de controle que operam de forma tentar conter formas de experimentação outras. Entretanto, as tentativas do cálculo, de previsão das experiências docentes e/ou mobilização de conhecimentos prévios para formação, são sempre falhas. Decidir no indecidível é, então, uma questão ética, de abertura ao risco do que não pode ser previsto - de abertura para a diferença. $\mathrm{O}$ direito de representação das práticas com o Trilhas é baseado numa diferença que se tenta arbitrar, com a intenção de transformar a parte no todo. Entretanto, a sombra, por exemplo, nas práticas consideradas inspiradoras, sempre permanece. Essa sombra desloca a autoridade e a expõe a presença perturbadora da ambivalência.

\section{As inspirações na arte da bailarina Pina Bausch}

A bailarina, coreógrafa e diretora Pina Bausch nasceu em Solingen, Alemanha. Iniciou seus estudos pela dança clássica aos 15 anos, formando-se em Dança e Pedagogia da Dança em 1958. Passou por escolas de dança em Nova Iorque e na Alemanha e, aos 33 anos, foi contratada para dirigir a companhia de dança Wuppertaler Tanztheater que, anos mais tarde, agregou o seu nome ao título, passando-se a chamar Wuppertaler Tanztheater Pina Bausch (Pina, 2019). A obra bauschiana destaca-se como uma proposta de contestação às formas prontas e à reprodução de coreografias que buscam conformar corpos. O processo de criação de seus espetáculos envolve a experimentação do corpo, sem a preocupação com a prescrição dos movimentos. Esse era o grande diferencial de suas peças que variavam a cada apresentação. Entre os temas recorrentes em suas obras, destacam-se as interações entre masculino e feminino, inspirando, inclusive, Pedro Almodóvar ${ }^{3}$ na criação do filme Fale com ela, em que Pina participa, apresentando uma sequência de dança. Pina Bausch era, então, conhecida pelas danças que contavam histórias. Suas coreografias eram pensadas em conjunto com seus atores-bailarinos e se baseavam nas experiências de cada um, incorporando um pedaço de suas vidas. Porém, cada gesto deveria remeter a um outro gesto imprevisível (Almeida, 2018).

As obras de Bausch nos inspiram para pensar na docência como performances em constante processo de diferimento que se lançam, continuamente, à possibilidade de surgimento do novo em um não lugar que não é "um fora" e nem "um dentro", mas um "entre" a realidade e a ficção (Almeida, 2018, p. 120). Almeida (2018) comenta, ainda, que os trabalhos de Pina fissuram a dualidade entre dança e teatro na contemporaneidade, de maneira que o teatro adentra a dança e vice-versa, através do estímulo ao improviso de cada um do seu elenco, no movimento das memórias de infância, desejos e angústias. O filósofo português José Gil (2004, p.178-179 apud Almeida, 2018, p. 120), observa que, em suas criações, Pina Bausch não se limita aos gestos habituais de cada situação:

[...] não se limita a atualizar a géstica do pensamento e das emoções que envolve qualquer situação. As improvisações a propósito de um tema podem provocar 
associações de palavras que o gesto transporta consigo e que remetem eventualmente para outros gestos, outras palavras e outros pensamentos [...] não utiliza, pois, de uma só maneira a relação palavra-gesto; sobretudo, porque não constrói um tipo apenas de gestos. [...] Os seus gestos podem assim parodiar os do ballet clássico ou reproduzir uma cena "real" de violência entre os dois membros de um par; podem sugerir os gestos do circo, bem como dos jogos infantis; etc. O enxerto, a associação, o cruzamento, a sobreposição incessante de inumeráveis tipos de gestos codificados e conhecidos tornam-se apêndices, variações e prolongamentos de um outro gênero de gestos [...] (2004, p.178-179 apud Almeida, 2018, p. 120).

Desse modo, por meio de atos transgressivos, as criações bauschianas tensionam as fronteiras dos campos das atividades humanas (Almeida, 2018). Almeida (2018) acrescenta que, sob seu ponto de vista, as criações realçam as descontinuidades e avivam uma atitude desconstrucionista ao levarem para o palco gestos cotidianos presentes em diversas práticas que, através da repetição e de remetimentos contínuos, rompem significados únicos de movimentos padronizados. Nos trabalhos de Bausch, o significado nunca é fixo e estável, ou seja, a significação se encontra num movimento permanente de busca do 'significante do significante'. 'Dessa maneira, os remetimentos constantes acabam por impedir que o significante esteja presente em si mesmo, passando então a se constituir a partir dos rastros de outros." (Almeida, 2018, p. 120).

A arte de Pina contribuiu para as reflexões sobre o processo de significação em sala de aula como rompimentos contínuos da linearidade do tempo e sobre a impossibilidade da transparência do fato, sua totalidade. A arte da docência, como a arte do remetimento ao outro nas suas diferenças, transita numa linha tênue entre as dimensões do pedagógico e do performático a que Bhabha (2013) se refere, ao discutir o movimento da autoridade colonial como movimentos que se interpenetram. A dimensão do pedagógico relaciona-se à tradição, impossível de ser descartada, algo que Derrida (2004 apud Almeida, 2018) menciona como a impossibilidade de se evadir da metafísica que alicerça o pensamento. Porém, devido ao próprio ato de repetição, a autoridade é sempre enunciada de forma diferente. Neste sentido, na dimensão pedagógica, a autoridade é produzida de modo ambivalente, em função dos processos de tradução através do qual os sentidos são contestados.

$\mathrm{Na}$ discussão sobre a arte de Pina Bausch, enfatizamos que não é apenas a forma de trabalho docente e sua rotina que diferencia a prática em sala de aula. A execução dessas práticas, sob o enfoque experimental, acaba por fazer surgir outros corpos e subjetividades, abrindo-se a um feixe de atividades não previstas, por exemplo, no Curso EAD do Trilhas. Neste sentido, "é justamente na (im)possibilidade, condicionada também pela oscilação entre práticas de rotina e o novo constante, que está a produtividade da tradução, seu potencial poético, social e cultural" (Klein, 2018, p. 400). Klein (2018) observa a existência de um planejamento na dança bauschiana que transita na ordem da imprevisibilidade.

Essa é uma questão importante para pensarmos que o planejamento - a norma - faz parte do dia a dia em sala de aula. Porém, é da ordem do (im)possível, na medida em que 
vivenciado, abre-se para outras possibilidades de sentidos. Portanto, há algo incomensurável na prática docente que transcorre em função dos processos de negociação da verdade proposta pelo Trilhas, rompendo constantemente a lógica sequencial, uma vez todos estamos enredados que em deslocamentos de tempos descontínuos, mobilizando múltiplas possibilidades de significação, em função das relações com o outro.

Temos refletido sobre as bandeiras suscitadas nessas Redes Transnacionais em trono das lutas pela melhoria da qualidade na educação pública, pela formação de leitores e escritores, por um Brasil alfabetizado, com uma sociedade respeitada em seus direitos por melhores condições de vida e justiça social. Parafraseando, Lopes e Borges (2015, p. 501), estamos comprometidas com os "projetos de mudar o mundo". Contudo, essas bandeiras tão propagandeadas nesse movimento público-privado se desvanecem quando outras são levantadas que resultam no apagamento das diferenças. Em diálogo, ainda, com as ideias de Lopes e Borges (2015), corroboramos com o necessário rompimento dos binarismos - certo ou errado; bom ou ruim - na luta por uma educação pública, plural, caminhando na contramão de um horizonte universalizante para o trabalho do professor alfabetizador, sob a ênfase de que as diferenças devem ser pensadas num processo de alteridade, ou seja, o outro também significa o processo de ensino-aprendizagem e se significa nesse processo.

\section{Considerações finais}

Os poetas iluminam o mundo com imagens e metáforas que estão distantes do discurso diário, mas, no entanto, descobrem a intensidade imaginativa e verbal que está escondida nas coisas cotidianas - talvez um frasco no Tennessee, ou uma rosa descontraída, ou mesmo sapatos de camurça azul (Bhabha, 2015, parag. 3, 3 tradução nossa) ${ }^{4}$.

A intensidade imaginativa e verbal, a que Bhabha (2015) se refere na passagem acima, escondida nos detalhes das "coisas" cotidianas, enaltece, não somente a poética que, no nosso entendimento, também perfaz a política curricular, mas a possibilidade de desconstrução dessa política. Não estamos nos referindo à desconstrução como desvelamento na busca de um sentido original. Mas, entendemos que "um sapato de camurça azul ou uma rosa descontraída" (Bhabha, 2015) expressa a necessidade da percepção de outras produções de sentidos, deslocadas, invisibilizadas pelas forças do poder discursivo.

Nossas reflexões visam, portanto, contribuir para as fissuras nas tentativas de fixação de sentidos para a prática em sala de aula, destacando a arte da docência como a arte da experiência viva e contínua. Por conseguinte, colocamos sob suspeita a possibilidade de soluções que vêm sendo apresentadas no movimento político-curricular para as dificuldades vivenciadas no dia a dia da sala de aula. Aliás, o fato de se pensar na instância da prática já requer o necessário questionamento à sua existência (Amorim; Macedo; Macedo, 2008), pois compreendemos que a prática não pode ser definida como algo dado previamente - calculado - tampouco pode ser definida a partir de um resultado a ser alcançado. Isto porque o professor 
está imerso em processos de negociação e, mesmo tentando seguir um projeto proposto, nunca conseguirá na sua totalidade, uma vez que a "rotina" é negociada o tempo todo com o outro.

Nesse sentido, defendemos uma outra dimensão para o protagonismo docente: não como aquele que está no foco das políticas, sendo apontado como responsável exclusivo pelo êxito - ou fracasso escolar -, mas aquele que também é protagonista do processo de significação, que negocia o sentido de prática e o sentido sobre o que vem a ser trabalho docente. Parafraseando Drummond (2019), aquele que tem o direito de significar o que entende por prática docente e se performa nas "coisas" cotidianas... na intensidade imaginativa que mobiliza as suas experiências em sala de aula e vai também se deslocando nesse processo; um processo de vidas que não são previstas, mas vividas.

\section{Notas:}

1. A "idade certa" é considerada - no projeto - aos 7 anos de idade para que a criança esteja plenamente alfabetizada. No entanto, a própria ideia de idade certa é problematizada por alguns estudiosos da alfabetização, como Axer (2019) que, ao pesquisar sobre a Política Nacional de Alfabetização na Idade Certa (PNAIC), discute a impossibilidade de fixação de uma idade dada como certa, tendo em vista o processo tão subjetivo e individual que é o processo de alfabetização.

2. Disponível em: https://sedu.es.gov.br/paes. Acesso em: 10 set. 2021.

3. Pedro Almodóvar Caballero é ator, produtor de cinema e roteirista, sendo um dos mais premiados realizadores da história do cinema. (Pedro, 2020).

4. "[...] Poets illuminate the world with images and metaphors that are distant from daily discourse, but nevertheless uncover the imaginative and verbal intensity that lies concealed in everyday things - perhaps a jar in Tennessee, or a rambling rose, or even blue suede shoes. [...]" (Bhabha, 2015).

\section{Referências}

ALMEIDA, Marcia Furlan de. A desconstrução derridiana e o processo criativo de Pina Bausch. ETD Educação Temática Digital, v. 20, n. 1, p. 118, 15 jan. 2018. DOI 10.20396/etd.v20i1.8647809. Disponível em: https://periodicos.sbu.unicamp.br/ojs/index.php/etd/article/view/8647809. Acesso em: 11 dez. 2019.

AMORIM, Antonio Carlos; MACEDO, Elizabeth; MACEDO, Roberto Sidnei (Org.). Como nossas pesquisas concebem a prática e com ela dialogam? Campinas, SP: FE/UNICAMP, 2008.

AVELAR, Marina; BALL, Stephen J. Mapping new philanthropy and the heterarchical state: The Mobilization for the National Learning Standards in Brazil. International Journal of Educational Development, $n$. In Press, nov. 2017. DOI 10.1016/j.ijedudev.2017.09.007. Disponível em: https://doi.org/10.1016/j.ijedudev.2017.09.007

AXER, Bonnie. Um olhar sobre a disputa de sentidos para alfabetização no PNAIC. Revista Panorâmica, v.28, jul/dez, 2019.

BALL, Stephen J. Educação global S. A.: novas redes políticas e o imaginário neoliberal. Ponta Grossa, PR: UEPG, 2014.

BHABHA, Homi K. O local da cultura. 2. ed. Belo Horizonte, MG: UFMG, 2013.

CAMÕES, Maria Clara L. S. O currículo como um projeto de infância: afinal o que as crianças têm a dizer? 
2019. 186 f. Tese (Doutorado em Educação) - Faculdade de Educação, Universidade do Estado do Rio de Janeiro, Rio de Janeiro, 2019.

BHABHA, Homi K. Why Humanities? 29 jun. 2015. Department of Communication Skills. [Blog]. Disponível em: https://csmefgi.blogspot.com/2015_06_01_archive.html. Acesso em: 2 fev. 2020.

DERRIDA, Jacques; STIEGLER, Bernard. Echographies of television: filmed interviews. Cambridge, UK; Malden, MA: Polity; Blackwell, 2002.

DRUMMOND, Rosalva de Cássia Rita. Do Direito à Educação aos Direitos de Aprendizagem: a escola sub judice. 2019. 196 f. Tese (Doutorado em Educação) - Faculdade de Educação, Universidade do Estado do Rio de Janeiro, Rio de Janeiro, 2019.

FILHO, Osvaldo Fontes. Uma "possibilidade impossível de dizer": o acontecimento em filosofia e em literatura, segundo Jacques Derrida. São Paulo: Trans/Form/Ação, v. 35, n. 2, p. 143-162, maio/ago, 2012.

FRANGELLA, Rita de Cássia Prazeres. Políticas de formação do alfabetizador e produção de políticas curriculares: pactuando sentidos para formação, alfabetização e currículo. Práxis Educativa, v. 11, n. 1, p. 107-128, 2016. DOI 10.5212/PraxEduc.v.11i1.0005. Disponível em: http://www.revistas2.uepg.br/index.php/praxiseducativa/article/view/7110/4759. Acesso em: 2 fev. 2020.

FRANGELLA, Rita de Cássia Prazeres; DIAS, Rosanne Evangelista. Os sentidos de docência na BNCC: efeitos para o currículo da educação básica e da formação/atuação de professores. Educação Unisinos, v. 22, n. 1, p. 7-15-15, 14 jan. 2018. DOI 10.4013/edu.2018.221.01. Disponível em: http://revistas.unisinos.br/index.php/educacao/article/view/edu.2018.221.01. Acesso em: 12 dez. 2019.

INSTITUTO NATURA. Acompanhe as ações da Rede de Apoio à Educação (RAE). 5 nov. 2018b. Instituto Natura. Disponível em: https://www.institutonatura.org.br/blog/acompanhe- as-acoes-da-rede-de-apoioeducacao-rae/. Acesso em: 18 dez. 2019.

INSTITUTO NATURA. Bem-vindo ao novo Portal Trilhas. 2019. Portal Trilhas. Disponível em: https://portaltrilhas.org.br/inicio. Acesso em: 24 nov. 2019.

INSTITUTO NATURA. Curso de leitura em voz alta pelo professor do Portal TRILHAS. 8 out. 2018a. Portal Trilhas. Disponível em: https://ead-trilhasproducao.s3.amazonaws.com/uploads/support_material/file/5bbe01e181bb73471b84d320/ma nual-cursosEAD-v03.pdf. Acesso em: 15 dez. 2018.

INSTITUTO NATURA. O que é o Projeto TRILHAS? 2015a. Portal Trilhas. Disponível em: https://legado.portaltrilhas.org.br/download/biblioteca/apresentacao-trilhas-articulador- $\quad$ estadual20150204190138.pdf.

INSTITUTO NATURA. Projeto Trilhas é aprovado no Guia de Tecnologias do Ministério da Educação (MEC) em 2015. 2015b. Disponível em: http://www.institutonatura.org.br/projeto-trilhas-e-aprovado-noguia-de-tecnologias-do- ministerio-da-educacao-mec-em-2015/. Acesso em: 17 dez. 2018.

INSTITUTO NATURA. Sobre nós: nossa visão. 2016. Disponível em: http://www.institutonatura.org.br/instituto-natura/. Acesso em: 9 dez. 2018.

KLEIN, Gabriele. Passing on Dance: practices of translating the choreographies of Pina Bausch. Revista Brasileira de Estudos da Presença, v. 8, n. 3, p. 393-420, set. 2018. DOI 10.1590/2237-266078975. Disponível em: http://www.scielo.br/scielo.php?script=sci_arttext\&pid=S223726602018000300393\&lng=en\&tlng=en. Acesso em: 3 fev. 2020.

LABORATÓRIO DE EDUCAÇÃO. Estudo de caso: monitoramento da implementação do pacto nacional pela alfabetização na idade certa. São Paulo, SP: Laboratório de Educação, 2014. Disponível em: http://labedu.org.br/wp-content/uploads/2017/07/Pesquisa- PNAIC.Compressed.pdf.

LOPES, Alice Casimiro; BORGES, Veronica. Formação docente, um projeto impossível. Cadernos de Pesquisa, v. 45, n. 157, p. 486-507, set. 2015. DOI 10.1590/198053143065. Disponível em: http://www.scielo.br/scielo.php?script=sci_arttext\&pid=S0100- $15742015000300486 \& \operatorname{lng}=$ pt\&tlng=pt. 
Acesso em: 3 fev. 2020.

LOPES, Alice Casimiro; CUNHA, Erika Virgílio Rodrigues da; COSTA, Hugo Heleno Camilo. Da recontextualização à tradução: investigando políticas de currículo. Currículo sem Fronteiras, v. 13, n. 3, p. 392-410, 2013. Disponível em: http://www.curriculosemfronteiras.org/vol13iss3articles/lopes-cunhacosta.pdf. Acesso em: 20 abr. 2015.

MACEDO, Elizabeth. A noção de crise e a legitimação de discursos curriculares. Currículo sem Fronteiras, v. 13, n. 3, p. 436-450, 2013. Disponível em: http://www.curriculosemfronteiras.org/vol13iss3articles/emacedo.pdf. Acesso em: 2 fev. 2020.

MACEDO, Elizabeth; FRANGELLA, Rita de Cássia Prazeres. Apresentação: políticas de currículo ou base nacional comum: debates e tensões. Educação em Revista, v. 32, n. 2, p. 13-17, jun. 2016. DOI 10.1590/0102-4698032021. Disponível em: http://www.scielo.br/scielo.php?script=sci_arttext\&pid=S0102-. Acesso em: 9 jun. 2017.

MACEDO, Elizabeth; RANNIERY, Thiago. Políticas públicas de currículo: diferença e a ideia de público. Currículo sem Fronteiras, v. 18, n. 3, p. 739-759, 2018. Disponível em: http://www.curriculosemfronteiras.org/vol18iss3articles/macedo-ranniery.pdf. Acesso em: 17 nov. 2019.

MARTINS, Beatris Alves; AXER, Bonnie; LUCENA, Vanessa Soares de. Rastros Políticos Formativos: um currículo nacional para a alfabetização chamado PNAIC. In: FRANGELLA, Rita de Cássia Prazeres (org). Políticas Curriculares, Alfabetização e Infância: por outras passagens. Curitiba: Editora CRV, p. 61-80, 2021.

MINISTÉRIO DA EDUCAÇÃO (Brasil). Base Nacional Comum Curricular. 3. versão. 2016. Ministério da Educação. Disponível em: http://basenacionalcomum.mec.gov.br/a-base. Acesso em: 12 set. 2021.

MINISTÉRIO DA EDUCAÇÃO (Brasil). Portaria no 867 de 4 de julho de 2012. Institui o Pacto Nacional pela Alfabetização na Idade Certa e as ações do Pacto e define suas diretrizes gerais. 5 jul. 2012. Inep. Disponível em: http://download.inep.gov.br/educacao_basica/provinha_brasil/legislacao/2013/portaria_n867_ 4julho2012_provinha_brasil.pdf. Acesso em: 3 fev. 2020.

PEDRO Almodóvar. In: Wikipédia, a enciclopédia livre. San Francisco, CA: Wikimedia Foundation, 14 jan. $2020 . \quad$ Disponível em: https://pt.wikipedia.org/w/index.php?title=Pedro_Almod\%C3\%B3var\&oldid=57177885. Acesso em: 3 fev. 2020.

PERONI, Vera Maria Vidal; OLIVEIRA, Regina Tereza Cestari de; FERNANDES, Maria Dilnéia Espíndola. Estado e terceiro setor: as novas regulações entre o público e o privado na gestão da educação básica brasileira. Educação \& Sociedade, v. 30, n. 108, p. 761-778, out. 2009. DOI 10.1590/S010173302009000300007. Disponível em: http://www.scielo.br/scielo.php?script=sci_arttext\&pid=S0101 $73302009000300007 \& \operatorname{lng}=$ pt\&tlng=pt. Acesso em: 2 fev. 2020.

PINA Bausch. In: Wikipedia. San Francisco, CA: Wikimedia Foundation, 16 dez. 2019. Disponível em: https://en.wikipedia.org/w/index.php?title=Pina_Bausch\&oldid=931054701. Acesso em: 3 fev. 2020.

RAMOS, Mozart Neves. Movimento Colabora Educação. 8 nov. 2017. Instituto Ayrton Senna. [Originalmente publicado em IstoÉ Online]. Disponível em: https://www.institutoayrtonsenna.org.br/ptbr/conteudos/movimento-colabora-educacao.html. Acesso em: 13 set. 2021.

SISCAR, Marcos. Jacques Derrida: literatura, política e tradução. Campinas: Autores Associados, 2012.

TODOS PELA EDUCAÇÃO. Alfabetização em regime de colaboração: o que falta o Brasil aprender? 28 fev. 2019. Educação e etc - Estadão. [Blog]. Disponível em: https://educacao.estadao.com.br/blogs/educacaoe-etc/alfabetizacao-em-regime-de- colaboracao-o-que-falta-o-brasil-aprender/. Acesso em: 13 dez. 2019. 


\section{Correspondência}

Ana Paula Pereira Marques de Carvalho: Doutora em Educação pela Universidade do Estado do Rio de Janeiro (UERJ) e Coordenadora do Programa de Bolsas de Iniciação Científica da UERJ.

E-mail: app_marques@yahoo.com.br

Nataly da Costa Afonso: Mestre em Educação pela Universidade do Estado do Rio de Janeiro, onde atualmente cursa o Doutorado em Educação. Professora de Anos Iniciais, atuando na função de Coordenadora Pedagógica na Secretaria Municipal de Educação do Rio de Janeiro (SME-RJ).

E-mail: nataly.uerj@gmail.com

Texto publicado em Currículo sem Fronteiras com autorização dos autores. 